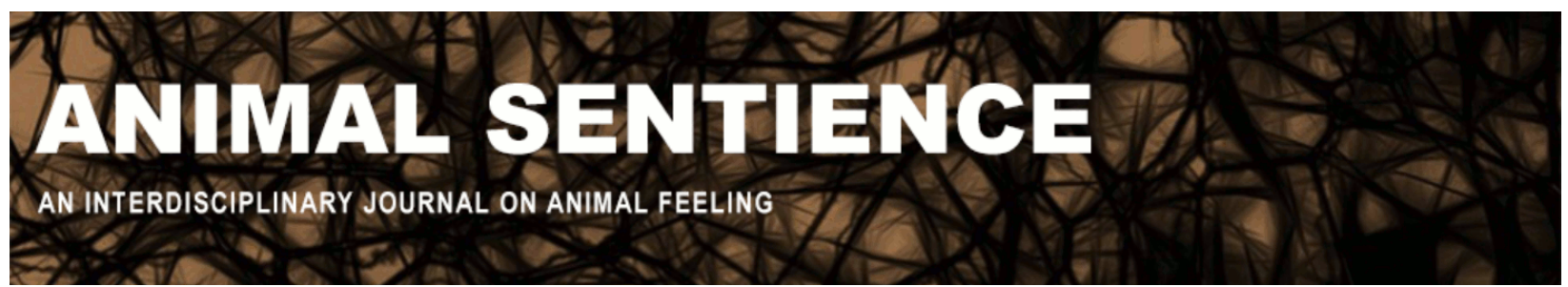

Peña-Guzmán, David M. (2017) Can nonhuman animals commit suicide?. Animal Sentience 20(1)

DOI: $10.51291 / 2377-7478.1201$

Date of submission: 2017-04-28

Date of acceptance: 2017-12-18

(c)

This article has appeared in the journal Animal

Sentience, a peer-reviewed journal on animal

cognition and feeling. It has been made open access,

free for all, by WellBeing International and deposited

in the WBI Studies Repository. For more information,

please contact

wbisr-info@wellbeingintl.org.

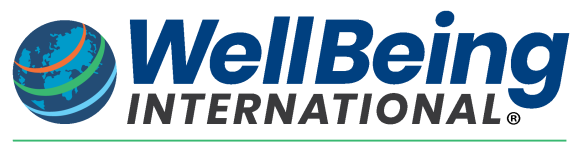

SOLUTIONS FOR PEOPLE, ANIMALS AND ENVIRONMENT 
Call for Commentary: Animal Sentience publishes Open Peer Commentary on all accepted target articles. Target articles are peer-reviewed. Commentaries are editorially reviewed. There are submitted commentaries as well as invited commentaries. Commentaries appear as soon as they have been reviewed, revised and accepted. Target article authors may respond to their commentaries individually or in a joint response to multiple commentaries.

Instructions: http://animalstudiesrepository.org/animsent/guidelines.html

\title{
Can nonhuman animals commit suicide?
}

\author{
David M. Peña-Guzmán \\ Humanities and Liberal Studies \\ San Francisco State University
}

\begin{abstract}
Many people believe that only humans have the cognitive and behavioral capacities needed for suicidal behavior, such as reflexive subjectivity, free will, intentionality, or awareness of death. Three counterarguments - based on (i) negative emotions and psychopathologies among nonhuman animals, (ii) the nature of self-destructive behavior, and (iii) the problem of model fidelity in suicide research - suggest that self-destructive and selfinjurious behaviors among human and nonhuman animals vary along a continuum.
\end{abstract}

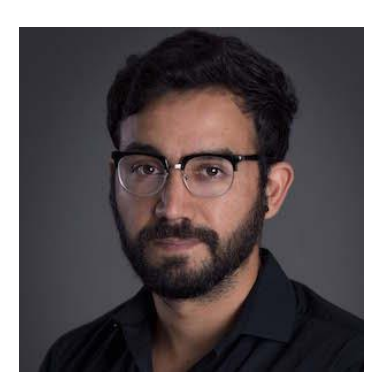

David M. Peña-Guzmán is Assistant Professor in Humanities and Liberal Studies at San Francisco State University. He holds an M.A. and a Ph.D. in Philosophy from Emory University. His interests include animal cognition and behavior, the history and philosophy of science, continental philosophy, and social theory.

www.humanitiesliberalstudies.sfsu.edu/people/381/david-peña-guzman

\section{The Case Against Animal Suicide}


Suicide is a complex phenomenon. In the case of human beings, it raises thorny questions about life and death that perhaps no living being is in a position to answer. This may be why Camus (1955) once said: "there is only one really serious philosophical question, and that is suicide" (p. 3). Curiously, the concept of suicide seems to lose all its complexity when applied to nonhuman animals because so many people take it to be self-evident that nonhuman animals lack the emotional and cognitive wherewithal to commit what Shneidman (1985) calls "murder in the one hundred and eightieth degree." For them, the concept of animal suicide can only be a joke, a category mistake, or an anthropomorphic illusion. ${ }^{1}$ They typically respond to the suggestion that some animals may engage in suicidal behavior by making suicide contingent on certain functions or capacities that only human beings are presumed to possess, such as self-reflective subjectivity, free will, or awareness of death. These appeals are inconclusive, however. They conflict with empirical research about the capacities of nonhuman animals and rely on problematic assumptions about the place of homo sapiens in the order of things.

\subsection{Reflexive Subjectivity}

One view is that suicide is possible only for animals endowed with a form of subjectivity that includes not only sentience, but also a specific kind of self-reflective subjectivity (henceforth "reflexivity") whereby an animal is capable of grasping itself as an agent capable of action (i.e., as an "I"). Suicide, on this view, is a fundamentally reflexive act in which the agent is simultaneously subject and object. As such, it requires a level of subjective sophistication that animals simply do not have. ${ }^{2}$

This view suffers from two shortcomings. The first is conceptual as much as empirical: it assumes that reflexivity is an all-or-none dichotomy and that animals either have it or lack it absolutely. Yet we have no reason - at least not since Darwin put humans and animals on a natural continuum in On the Origin of Species (1859) and The Descent of Man (1871) - to expect such discontinuities in nature. In an article published in TRENDS in Ecology and Evolution in 2004, Bekoff and Sherman argue that natural diversity and biological evolution make it highly unlikely that there will ever be a single standard for typecasting animals into two simple classes: the have's and the have not's. There is no "acid-test for determining degrees of self-cognizance across all taxa" (p. 178). Following Darwin's continuity thesis, Bekoff and Sherman maintain that animals have different types and degrees of subjective selfawareness - types that cannot be reduced to "natural kinds," and degrees that cannot be easily quantified. A great deal of empirical research supports this continuist paradigm (DeGrazia 1996; Baars 2005; Seth, Baars, and Edelman 2005; DeGrazia 2006; Feinberg and Mallatt 2013; Tononi and Koch 2015; Rowlands 2016). ${ }^{3}$ This research challenges the conventional belief that self-cognizance sets humans (or even "big-brained creatures") apart from the rest of nature (Bekoff and Sherman 2004, p. 179).

\footnotetext{
${ }^{1}$ One example is Hooper (2010).

${ }^{2}$ Windt (1981) builds this requirement into his definition of suicide and argues that since nonhuman animals lack reflexive self-awareness, they cannot engage in suicide. Comai and Gobbi (2016) and Gould (2017) agree with the conclusion.

${ }^{3}$ The evidence for a continuist perspective is so strong that, according to Benvenuti (2016), it may soon require a wholesale reconfiguration of human-animal relations, beginning with a radical "rethinking of foundational concepts in law and health sciences" (p. 667).
} 
Bekoff and Sherman (2004) highlight the diversity of animals on this continuum by identifying at least three different types of subjectivity that crisscross the animal kingdom in elaborate and nonlinear ways (see Table 1), suggesting that self-cognizance is a continuum that evolves constantly (and in multiple directions) rather than a dichotomy that magically carves nature at its joints: "The degree of self-cognizance of individuals in any species can be represented as a point on a continuum of complexity and conscious involvement" (p. 176). Like everything else in nature, self-cognizance is a matter of degree rather than kind.

\begin{tabular}{|c|c|c|}
\hline \multicolumn{3}{|c|}{$\begin{array}{c}\text { Table } 1 \text { - Types of Subjectivity } \\
\text { Summary of Bekoff and Sherman }(2004)^{*}\end{array}$} \\
\hline $\begin{array}{l}\text { SELF-REFERENCING } \\
\text { SUBJECTIVITY }\end{array}$ & $\begin{array}{l}\text { Distinguishing between animals } \\
\text { that are members of one's own } \\
\text { species and those who are not. }\end{array}$ & $\begin{array}{l}\text { Entails "matching phenotypic } \\
\text { characteristics of a target individual } \\
\text { against the phenotype of the } \\
\text { discriminator." This type of subjectivity } \\
\text { "can be reflexive and non-cognitive, } \\
\text { even occurring in the immune system } \\
\text { and in creatures without brains" (p. } \\
\text { 177). }\end{array}$ \\
\hline SELF-AWARE SUBJECTIVITY & $\begin{array}{l}\text { Distinguishing between self and } \\
\text { other. }\end{array}$ & $\begin{array}{l}\text { Also referred to as "perceptual } \\
\text { consciousness," describes animals that } \\
\text { understand, even if only tacitly, the } \\
\text { boundaries of their own bodies and } \\
\text { differentiate between self and other ("I" } \\
\text { and "non-I") (ibid.). }\end{array}$ \\
\hline $\begin{array}{c}\text { SELF-CONSCIOUS } \\
\text { SUBJECTIVITY }\end{array}$ & $\begin{array}{l}\text { Thinking about one's behavior } \\
\text { in relation to the actions of } \\
\text { others. }\end{array}$ & $\begin{array}{l}\text { Also called "second-order thought" and } \\
\text { "meta-cognition," "leads to dynamic and } \\
\text { finely graded behavioral outputs, } \\
\text { ranging from cooperation to selfishness, } \\
\text { depending on the costs and benefits of } \\
\text { previous responses of conspecifics to } \\
\text { the focal individual" (ibid.). Most } \\
\text { common among animals who live in } \\
\text { social structures with plastic } \\
\text { hierarchies, such as primates. }\end{array}$ \\
\hline
\end{tabular}

Internal inconsistency is the second shortcoming of the view that only humans have reflexive subjectivity and hence only humans can commit suicide. Even if reflexivity were a natural dichotomy and a necessary condition for suicide, it still would not follow that the dichotomy maps neatly onto a species classification. Nor would it follow that only humans engage in suicide. There are humans whose suicidal behaviors have been documented but who may not meet the requirements of a theory of reflexive subjectivity, such as children (Stefanowski-Harding 1990; Matter and Matter 1984; Martin 2014; Heise, York, and Thatcher 2016; Bodzy et al. 2016). There are also nonhumans that regularly pass self-recognition tests and, at least by this standard, meet the requirements of reflexivity. Great apes, dolphins, elephants, and the Eurasian magpie, for example, have all passed Gallup's (1970) famous "mirror test," which many animal behavior experts consider evidence of reflexive, selfconscious subjectivity (Prior, Schwarz, and Güntürkün 2008), and which some human 
children fail up to the age of six (Willett 2014, p. 122). ${ }^{4}$ Hence, the argument that animals cannot commit suicide because they lack the right kind of subjectivity breaks down. To exclude all nonhumans from the domain of suicide, this argument would have to be construed quite stringently - in which case it would inevitably exclude some humans. Conversely, to effectively include all humans, it would have to be construed more liberally — in which case it would inevitably include some nonhumans.

\subsection{Free Will}

Some thinkers use the concept of free will as an argument against animal suicide, in part because this concept shapes our common-sense intuitions about suicide (Szasz 1986; Higonnet 1986; Hassana 1998; Douglas 2015). ${ }^{5}$ Inspired by a theological understanding of human beings as sites of transcendence, such thinkers hold that animals cannot commit suicide because suicide is an expression of free will, which only humans have. The problems with this line of reasoning are legion, but this section is limited to two for the sake of expediency: the problem of nonhuman free will and the problem of natural causality. ${ }^{6}$

Do animals such as cows, pigs, parrots, dogs, and orangutans have free will? Although this is inconsistent with theological orthodoxy, it is possible to claim they do. Some cultures already claim this, ${ }^{7}$ as do some experts on "voluntary behavior choice" and "positive reinforcement theory." The latter hold that animals are not passive agents in the research process, but active participants who can choose whether to participate in research out of their own volition (Berns, Brooks, and Spivak 2012; Tan and Hare 2013; Fenton 2014). ${ }^{8}$ In a 2012 article published in Biology \& Philosophy, Fenton argues that some animals (he focuses on chimpanzees) have the ability to dissent from various kinds of interactions with humans and that, consequently, research protocols that do not take this morally salient capacity into account may fail "ethical standard[s] for morally acceptable research" (p. 89). The Japanese primatologist Tetsuro Matsuzawa agrees. After decades of working with chimpanzees, Matsuzawa came to the conclusion that chimpanzees act freely and voluntarily. They act, as he says explicitly, "based on their free will" (Matsuzawa, 2006, p. 20). Like Fenton, he also believes that behavioral and biomedical research must accommodate chimpanzees' volitional and decisional capacities just as biomedical research involving human subjects must incorporate human beings' ability to consent to, and dissent from, medical care (p. 16).

Now, one could avoid attributing free will to nonhuman animals by following Steward (2015), who strikes a shaky balance between theological commitments to human exceptionalism and the growing body of empirical evidence that animals, too, can act freely (or at least as freely as humans) ${ }^{9}$ by differentiating between what she calls "full-blown free will" and "capacities for voluntary action." Only human beings have full-blown free will, she

\footnotetext{
${ }^{4}$ The mirror test is not infallible. But its main flaw is that it can yield false negatives, not false positives (Bekoff and Sherman 2004, p. 177).

${ }^{5}$ References to "free will" appear frequently in suicide notes (Cheung, Merry, and Sundram 2015).

${ }^{6}$ Two other objections to free will are that free will does not exist (Wegner 2003; 2004; Ebert and Wegner 2011) and that it is an incoherent concept (Mackie 1955).

${ }^{7}$ Some cultures already do this. Maya-descendant communities in Mexico's Yucatán peninsula view suicide as something that happens when an animal, human or nonhuman, loses its will to live (Braitman 2014, pp. 157-8). ${ }^{8} \mathrm{~A}$ number of animals, including rodents, can make informed decisions based on their own interests (Lahvis 2017).

${ }^{9}$ Palmer (2010) expresses the view that animals have no free will, but neither do humans.
} 
says, but many animals can act voluntarily. At first glance, this position seems reasonable enough, perfectly lodged between extremes. It satisfies theologians who emphatically assert that only humans have free will and natural scientists whose research indicates that animals are more than just Cartesian automata or Pavlovian black-boxes. Upon closer scrutiny, however, the position quickly proves unsustainable - indeed, unintelligible. As soon as we accept that animals have preferences, that they express and pursue these preferences in various contexts, that they plan ahead, that they sustain intentions for long periods of time, that they assent to and dissent from different situations, and that they make informed choices that are not pre-determined, it becomes quite difficult to see any meaningful difference between having full-blown free will and merely having the capacity to act freely. What empirically tractable difference does it make whether an animal has full-blown free will or only the capacity to act out of its own volition? Are there choices that an animal endowed with full-blown free will can make that an animal endowed with only voluntary-action capacities cannot? It does not appear so. This distinction then may be a textbook case of what William James (1995) once called "scholastic hair-splitting," a reference to the medieval practice of making linguistic distinctions devoid of empirical traction.

By definition, free will is a metaphysical concept. It denotes a force that is causally efficacious but that somehow stands outside the order of nature, that is, a force whose effects can be felt in the natural world but that is itself wholly unaffected by whatever happens in this world. ${ }^{10}$ As such, this concept has an anti-naturalistic air that may be incompatible with scientific epistemology in general and with contemporary understandings of suicide in particular. To define suicide in terms of free will is to place the phenomenon on a metaphysical pedestal just outside the reach of scientific practice and explanation - literally beyond (meta) nature (physis). Yet, it is not uncommon for scientists and laypeople to react to stories about suicidal animals (e.g., the case of the scorpion that stings itself when girted by fire or that of the rat that seeks out the smell of a cat and gets killed) by invoking this concept and asserting that these are not "true" suicides because they can be explained in terms of purely natural causes - for example, a simple reflex reaction in the case of the scorpion and the activity of the parasite Toxoplasma gondii in the case of the rat. ${ }^{11}$ Real suicides, they say, require an Augustinian "free choice of the will." The assumption that underlies this belief is that if a self-induced death can be explained naturalistically (by physical, chemical, biological, or psychological processes), it cannot be called "suicide." What shall we say, then, about self-induced human deaths that can also be explained in this manner?

Consider the case of anti-depressant drugs. It is a well-known fact that the risk of suicide increases during antidepressant drug treatment involving selective serotonin reuptake inhibitors (SSRIs). SSRIs, which are found in popular antidepressants like Prozac, Paxil, and Zoloft, affect the brain in such a way that patients who take them can experience

\footnotetext{
10 This is how philosophers and theologians from Hobbes and Descartes to Augustine and Aquinas have historically defined it - as liberum arbitrium. Proponents of free will often say an action cannot be "free" if it is determined by a cause external to the agent ("incompatabilism") or by a cause external to the agent other than God ("theological compatibilism").

${ }^{11}$ Preti (2011a) says "there is no evidence that parasite-induced behaviors are in any way comparable to the psychopathology leading to suicide in humans" (p. 819). However, Braitman (2014) observes that the same parasite that leads to suicidal acts in rats can also infect humans and lead them to engage in risky behaviors that we regularly deem suicidal (p. 180).
} 
many of the emotional states typically associated with suicide (depression, mania, aggression, etc.). ${ }^{12}$ Now, imagine that a patient on SSRIs commits suicide. Assuming that the science about the link between SSRIs and suicide does not change, ${ }^{13}$ we would readily accept a purely naturalistic explanation of the suicide. We would say: "The cause of the patient's death was the effect of SSRIs on her brain." We would not say: "The cause was her God-given, transcendental power to act in ways not determined by any causes."

Perlin (1994) observes that the old medieval view of suicide as "sinful" has given way to a modern interpretation of it as "environmental." Today, researchers look for the causal mechanisms involved in suicide; and they search for them in the domain of physical nature, not beyond it. No contemporary scientific theory explains suicide via the concept of free will. Neurological theories focus on the neurochemical processes concomitant with suicide. Psychological theories refer to the emotive and cognitive contents of the suicidal mind (thoughts, feelings, affects, tendencies). Sociological, epidemiological, and ecological theories focus on the social, environmental, and political factors that act upon individuals from without, such as poverty, homelessness, drug addiction, mental illness, features of the lived environment, patterns of social disorganization, and fractured systems of social signification (Jones 1982). Even though they disagree on many points, all these theories agree on one key point - namely, that the cause of suicide must be sought not in some metaphysical realm that is abstracted from the empirical world but in the empirical world itself. Durkheim (2002) made this point quite persuasively in his seminal 1897 study of suicide, where he rejected transcendental frameworks in favor of empirical ones (Douglas 2015).14 More than one hundred years later, science continues to follow Durkheim's lead. As of the writing of this article, no scientific theory of suicide incorporates free will into its explanatory space. Hence the question must be asked: If we no longer use the concept of free will to make sense of human suicide, why do we use it to make nonsense out of nonhuman suicide?

\subsection{Awareness of Death}

It is commonly said that to commit suicide an agent must intend to bring about its own death, which animals cannot do because they cannot "represent" or "conceptualize" death in the first place. But even if we assume, for the sake of argument, that animals lack a concept of death, it is still not clear why this should preclude them from engaging in suicide, especially when there are humans who engage in suicide but who may also lack this concept (e.g., children). ${ }^{15}$ Moreover, it is not self-evident that animals do indeed lack this concept. Death plays a more central role in the lives of numerous animals than we have previously imagined. Burial rituals have been observed in various animal species, including crows (BBC News 2015), magpies (Bekoff 2009a), captive gorillas (Morin 2015), red foxes (Bekoff 2009b), elephants, and

\footnotetext{
12 The FDA requires a black-box warning informing consumers about the increased risk of suicidal ideation and behavior associated with SSRIs.

${ }^{13}$ In recent years, the link between SSRIs and suicide has been contested (McCain 2009), though not disproven. The point here is not about SSRIs per se, but about the incompatibility between free will and scientific understandings of causality.

${ }^{14}$ Durkheim's (2002) theory, interestingly, excludes all considerations "related to the suicide of animals" (p. xliii).

15 There are also humans who are circumstantially incapable of conceptualizing their own death, such as the criminal who is surrounded by police, panics, and commits "suicide by cop," and the accident victim in extreme pain who refuses medical treatment, which Beauchamp and Childress (1978) insist on calling "suicide."
} 
dolphins (Goldman 2012). Furthermore, many animals - including pets likes cats and dogs and farm animals like horses, rabbits, and birds - experience feelings of bereavement, melancholia, and grief when relatives or companions die, which may mean survivors understand the difference between life and death (Angier 2008; King 2013; Bekoff 2009b). These feelings can be so acute that veterinarians recommend bereaved animals "be allowed to view the body of a recently deceased companion [... as] this may help with some sort of acceptance of the loss" (Wedderburn 2015, p. 1). Like their human counterparts, it seems, nonhuman animals need closure in the face of death; like us, they need to say good-bye. Walker, Waran, and Phillips's (2016) recent study of owners' perceptions of how their nonhuman companions respond to the death of another animal companion further supports this view.

Research in the emerging field of "Pan thanatology," which is the study of how members of the genus Pan relate to and process death, also shows that chimpanzees and bonobos have a grasp of death that goes beyond merely experiencing grief and sadness in the face of a loved one's passing. Members of this genus have rituals surrounding death, including communal norms for the treatment of moribund conspecifics and their bodies postmortem. Bonobos, for example, often prevent the deceased bodies of friends and relatives from being moved or touched by outsiders, even if this means risking harm to themselves (NOVA 2008), ${ }^{16}$ while chimpanzees treat sick and healthy conspecifics differently, just as they treat the bodies of the sick differently pre- and post-mortem (Anderson, Gillies, and Lock, 2010). Female chimpanzees have been filmed carrying the mummified remains of their infants on their backs for weeks or months after the infants have perished (Matsuzawa 1997; Biro et al. 2010). This behavior, which arguably disproves Varki and Brower's (2013) thesis that only humans can be "in denial" about death, has been documented in a wide range of mammals, including terrestrial mammals such as gorillas, baboons, macaques, lemurs, and geladas (Goldman 2012, p. 1), and marine mammals such as Indo-Pacific bottlenose dolphins, spinner dolphins, killer whales, Australian humpback dolphins, sperm whales, Risso's dolphins, and short-finned pilot whales (Reggente et al. 2016).

\section{The Case for Animal Suicide}

The scientists who openly defend the possibility of animal suicide are a minority. This could be because of the eccentricity of the topic, but also because of how most scientists currently in the apogee of their careers were trained to think and write about animals in the 1960s, '70s, '80s, '90s and early 2000s - namely, from a cool distance and with an air of skepticism, and without ever imputing emotions, feelings, or even mental states to animals for fear of sounding "anthropomorphic" (King 2013, p. 8; Bekoff 2007, p. xvii). Without realizing it, therefore, a good number of researchers may be self-selecting out of research topics that require discussing what Bekoff (2007) calls "the emotional lives of animals," including suicide. Either way, what should surprise us is not that there aren't more scientists who embrace the possibility of animal suicide openly, but that there are any who do. This suggests that there are scientifically sound reasons for believing that suicide may not be an exclusively human phenomenon.

16 Sichuan snub-nosed monkeys, though not members of the Pan genus, also provide "compassionate caregiving" to dying conspecifics with whom they share emotional bonds (Yang, Anderson, and Li 2016). 


\subsection{Negative Emotions and Psychopathologies}

Some researchers grant that some animals may have "the mental machinery to commit suicide" (Preti 2011b) because they can experience many of the emotional states typically connected with suicide (p. 2). A wide range of animals experience helplessness (Seligman 1972; Malkesman et al. 2009), lethargy (Anderson, Gillies, and Lock 2010), and many conditions symptomatic of depression, such as chronic anxiety, aggressiveness, sleep problems, and anhedonia (Preti 2011a). Some even exhibit pathologies homologous to human psychiatric disorders that are recognized as antecedents to suicide, including posttraumatic stress disorder, eating disorders, and anti-social, borderline, and schizoid personality disorders (Lilienfeld et al. 1999; O'Connor et al. 2001; Bradshaw 2005; Bruene et al. 2006). ${ }^{17}$ It is also revealing in this regard that we regularly diagnose animals using human psychological and psychiatric models ${ }^{18}$ and treat their mental disorders using drugs intended for human use. For example, it is not uncommon for domesticated and captive animals battling chronic anxiety and depression to be prescribed human antidepressants like Prozac, Xanax, and Paxil (Braitman 2014; Korte et al. 2007; Overall 2000), often with favorable outcomes (Crawley, Sutton, and Pickar 1985).

\subsection{Self-Destructive Behavior Parallels}

Nonhuman animals often engage in the same kinds of self-injurious and self-destructive behaviors that, in human beings, are described as "suicidal." Crawley, Sutton, and Pickar (1985) provide a helpful compendium of evidence of self-destructive behaviors among nonhuman animals that are "relevant to self-destructive and suicidal behaviors in humans" (p. 300), based on which they conclude that "humans are not alone in exhibiting self-initiated behaviors that ultimately produce self-harm or death" (p. 308) (see Table 2).

Admittedly, many of the behaviors listed by Crawley, Sutton, and Pickar (1985) have been explained by theories that make no reference to suicide. Evolutionary accounts of kinselection, for instance, successfully explain the altruistic behavior of hymenoptera, while ecological theories of population growth explain the dispersal behavior of lemmings. But there is a difference between how we explain the behavior and what we call it. Just as we explain the death of a patient on SSRIs by appealing to the effects of the drug and still call the death a "suicide," we may explain many of these behaviors in a number of ways and also call them "suicidal." Nonetheless, we may want to divide Crawley, Sutton, and Pickar's (1985) evidence into "weak" and "strong." Weak evidence would include general behavioral parallels between humans and nonhumans that are not suicide-specific, whereas strong evidence would include biological, chemical, neurological, and psychological parallels with a more direct link to suicide. Gould et al. (2017) recently described many of these parallels in detail, plus some additional ones not mentioned in Crawley, Sutton, and Pickar (1985), such as "neurotransmitter system abnormalities, endocrine and neuroimmune changes, [...]

\footnotetext{
${ }_{17}$ Table 2 in Preti (2011) offers a helpful list of all the negative emotions associated with suicide that afflict animals.

${ }^{18}$ One example of this is the Triarchic Psychopathy Measure (TriPM) developed by Patrick, Fowles, and Krueger (2009), and Patrick (2010). Originally intended for human applications and relying heavily on linguistic reports from patients, this metric is already being used with nonhuman animals for diagnostic purposes (Brüne 2006, p.1251). Recently, Latzman et al. (2016) created a psychopathy measure called "Chimpanzee Triarchic" (CHMPTri) that is modeled after TriPM and is designed to investigate psychopathic personality in chimpanzees.
} 
decision-making deficits, as well as the role of critical interactions between genetic and epigenetic factors" (Gould et al. 2017, p. 1).

\begin{tabular}{|c|c|c|c|}
\hline \multicolumn{4}{|c|}{$\begin{array}{l}\text { Table } 2 \text { - Self-Destructive Behaviors } \\
\text { Summary of Crawley, Sutton, and Pickar (1985) }\end{array}$} \\
\hline EVIDENCE & DESCRIPTION & \multicolumn{2}{|c|}{ EXAMPLES } \\
\hline \multirow[b]{2}{*}{$\begin{array}{l}\text { Laboratory } \\
\text { Research }\end{array}$} & \multirow{2}{*}{$\begin{array}{l}\text { Laboratory-based } \\
\text { research on the } \\
\text { psychological and } \\
\text { biological "parallels" } \\
\text { underpinning self- } \\
\text { destructive behavior } \\
\text { in human and } \\
\text { nonhuman animals }\end{array}$} & $\begin{array}{l}\text { PSYCHOLOGICAL } \\
\text { EXPERIMENTS }\end{array}$ & $\begin{array}{l}\text { Animals can develop conditions } \\
\text { homologous to depression, } \\
\text { anxiety, hopelessness, and } \\
\text { despair. a }\end{array}$ \\
\hline & & $\begin{array}{l}\text { BIOLOGICAL AND } \\
\text { BIOMEDICAL RESEARCH }\end{array}$ & $\begin{array}{l}\text { The same biological, } \\
\text { physiological, and neurological } \\
\text { factors implicated in human } \\
\text { suicide are also implicated in } \\
\text { cases of self-destructive } \\
\text { behavior in nonhumans. b }\end{array}$ \\
\hline \multirow{3}{*}{$\begin{array}{l}\text { Ethological } \\
\text { Observation }\end{array}$} & \multirow{3}{*}{$\begin{array}{l}\text { Field research on } \\
\text { nonhuman behaviors } \\
\text { that resemble } \\
\text { suicidal behavior in } \\
\text { humans }\end{array}$} & ALTRUISTIC BEHAVIORS & $\begin{array}{l}\text { When an animal sacrifices itself } \\
\text { for others. }{ }^{c}\end{array}$ \\
\hline & & DISPERSAL BEHAVIORS & $\begin{array}{l}\text { Generated by pressures in } \\
\text { population density that result } \\
\text { in the "expulsion of an } \\
\text { individual from the group." d }\end{array}$ \\
\hline & & $\begin{array}{l}\text { STRESS-RELATED } \\
\text { BEHAVIORS }\end{array}$ & $\begin{array}{l}\text { Involving captive animals, } \\
\text { resulting in self-harm e }\end{array}$ \\
\hline \multicolumn{4}{|c|}{$\begin{array}{l}\text { a e.g., experiments on "learned helplessness" in rodents and "social separation" in primates } \\
\text { b e.g., "resistance to the dexamethasone suppression of cortisol," "low cerebrospinal fluid 5-HIAA," and "disturbances in the link } \\
\text { between serotonergic systems and the hypothalamic-pituitary-adrenal axis" (pp. 305-7) } \\
\text { c e.g., the "soldering" behavior of hymenoptera, the "herding" behavior of cattle and fish, and the alarm calls and "kamikaze" defense } \\
\text { mechanisms of blackbirds, warblers, jays, robins, and hummingbirds (pp. 301-2) } \\
\text { d commonly observed in arctic ground squirrels, rats, mice, and lemmings (pp. 302-3) } \\
\text { e self-aggression, self-fighting, self-biting, self-mutilation, and self-endangerment (via refusal to eat) (p. 303) }\end{array}$} \\
\hline
\end{tabular}

Consider, as a candidate for strong evidence, the self-destructive behaviors of cetaceans and, more specifically, the controversial topic of dolphin suicide. In the AcademyAward-winning documentary The Cove (2009), dolphin trainer and animal rights activist Richard O'Barry claims to have observed a dolphin named Kathy kill herself by willingly choosing not to breath. According to O'Barry, Kathy, who appeared in the popular 1960s show Flipper, was severely depressed after living her entire life in captivity. At some point, he says, she probably lost her will to live and killed herself: "These are self-aware creatures with a brain larger than a human brain. If life becomes so unbearable, they just don't take the next breath. It's suicide" (Nobel 2010, p. 1).

To skeptical ears, this story reeks of anthropomorphism. It seems to project onto a dolphin a range of mental and motivational states that presumably only humans experience. Yet, according to Naomi Rose, a world-renowned expert on orca behavior and a member of the International Whaling Commission's Scientific Committee, O'Barry's suggestion is not as implausible as some might think (Braitman 2014, p. 167). She is not alone in this view. Marino (2016), an expert in dolphin cognition whose research first showed that some dolphins pass Gallup's mirror test, agrees with her. In a white paper on dolphin suicide, Marino claims, "the behavioral, cognitive, neurological and physiological evidence suggests it is possible that dolphins possess the ability to end their own lives" (p. 1). She gives three reasons for this view. 
First, dolphins are extraordinarily intelligent mammals capable of self-awareness and metacognition. They recognize themselves in a mirror (Reiss and Marino 2001), "demonstrate awareness of their own bodies in a variety of other ways" (Mercado et al. 1998, 1999), and display high-level social cognition (Marino 2016, pp. 1-2). Second, dolphins have large, complex brains: "The dolphin neocortex (the evolutionarily newest part of the brain involved in higher-order thinking) is massive and even more convoluted than that of humans." Also, the dolphin limbic system, a series of neural structures and circuits that control long-term memory and emotion, "is particularly elaborated," which suggests dolphins "possess a sophisticated capacity for emotion and the kinds of thinking processes that would be involved in complex motivational states, such as those that accompany thoughts of suicide" (ibid., p. 2). And third, the nature of dolphin respiration provides a viable mechanism for the execution of suicide. Unlike humans, dolphins are voluntary breathers. Each breath they take reflects a conscious decision they make. "They do not have the involuntary inhalation response that causes humans and other land animals to breathe in water and drown. Instead, dolphins can hold their breath indefinitely until they die from hypoxia. This provides a physiological mechanism that would make the voluntary cessation of breathing a realistic possibility" (ibid.). ${ }^{19}$ Marino concludes that dolphins may be capable of intending and completing suicide. She adds, however, that "[t]his conclusion is tentative because it is difficult to confirm subjective states in other beings and, in particular, those who do not share our language" (ibid.). Even if we doubt O'Barry's particular story, the evidence suggests that the capacity for suicide "may exist in dolphins" (ibid.). King (2013) echoes this claim, arguing that the hypothesis of dolphin suicide cannot be ruled out even when military sonar technology is proven to play a role in the self-inflicted death of a dolphin (p. 122). [See also King 2016 and accompanying commentaries, this journal. - ed.]

In general, the evidence for self-injurious and self-destructive behavior in animals is significant. In a 2007 report, Preti reviewed all the research on the subject of animal suicide published between 1967 and 2007 in the Medline/PubMed and PsychINFO databases to find out whether the available evidence supported the belief that animals engage in suicidal behavior. His comprehensive review yielded ample evidence for this belief. Many animals, especially captive and isolated ones, engage in self-destructive behaviors that run the full gamut from self-mutilation to self-cannibalism (p. 834). Some of the species mentioned in Preti's report include rhesus monkeys, rabbits, rats, psittacine birds, and octopi, although the list is not exhaustive. Elsewhere, Preti builds on this by indicating that many animals starve themselves to death voluntarily if captured or separated from loved ones, whereas others self-destroy while in the throes of psychopathology. Still others simply lose interest in species-typical, life-enhancing activities if they find themselves in suboptimal living conditions, especially those "perceived as uncontrollable" (Preti 2011a, p. 819). Preti (2007) ends on a note similar to Marino's: while existing evidence does not prove animals commit suicide, it demonstrates that this possibility cannot be "rejected a priori" (p. 843).

\subsection{The Dilemma of Model Fidelity in Suicide Research}

Models are conceptual representations that help scientists explain and predict natural phenomena. With them, scientists give accounts of the causal mechanisms involved in

\footnotetext{
${ }^{19}$ Rose accepts other mechanisms of dolphin suicide, including refusal to eat and refusal to engage with others, both of which bring about a slow death (Braitman 2014, p. 168).
} 
different kinds of phenomena and make estimations about the future behavior of natural systems. Models facilitate what philosophers of science call "surrogate reasoning," which is an epistemic maneuver whereby one makes inferences about a target system by observing the behavior of a model, making predictions about its future behavior and extrapolating from model to target. In the philosophy of science literature, models that capture enough of the causal relationships of a target system to help scientists make reliable inferences about its behavior are said to be "of a high order of fidelity." Models that fail to expedite scientific explanation and prediction, by contrast, are considered "of a low order of fidelity."

While animal models are ethically controversial (DeGrazia 2016; DeGrazia and Sebo 2015; Conlee 2012), they are used regularly in human suicide research, ${ }^{20}$ where they are viewed as "formidable tools to investigate the etiology of an illness, its course, and potential treatment" (Preti 2011a, p. 818). Most suicide researchers believe, explicitly or implicitly, that there is a clear and testable link between animal models and their target systems and that, as a consequence, the former are of a high order of fidelity (Lipsaka 2000) - otherwise they would not use these models in their research, let alone treat them as reliable springboards for surrogate reasoning (Preti 2011a, p. 818). In effect, faith in the validity of animal models is so strong in this field that researchers often praise them as being triply valid, which is to say, as being valid in three senses: (1) in the sense of having a high degree of "correspondence" or "similitude" with their target mechanism ("face validity"), (2) in the sense of inducing behavioral changes in animals "that can be monitored and reversed by the same treatment modalities that are effective in humans" ("predictive validity"), and (3) in the sense of capturing causally significant biological, chemical, and neurological pathways in animals comparable to those operative in human biology and behavior ("etiological validity") (ibid.).

I take no stance here on whether animal models are of a high or a low order of fidelity relative to their target systems in suicide research. I do, however, claim that scientists' commitment to their use has implications for animal suicide. Currently, researchers use animal models to study the emotional states that are viewed as antecedents to suicide, the self-destructive behaviors of human beings, and the "biological intermediaries" that in humans lead from emotional antecedent to behavioral effect (say, from psychopathology to self-destruction). This implies that animals can experience some of the emotions and psychopathologies that lead to suicide in human beings (Malkesman et al. 2009, p. 165), that animals can engage in the sorts of behaviors that in human beings are labeled "suicidal," and that the intermediary processes are similar in humans and animals (or, at least, similar enough to permit surrogate reasoning in suicide research) (Crawley, Sutton, and Pickar 1985; Preti 2011a). Our best research practices, then, commit us to the view that nonhuman animals (i) experience the emotional and psychological conditions that, in human beings, cause suicide; (ii) display behaviors that, in human beings, are exemplary of suicide; and (iii) undergo the same biochemical and biological process on the road from (i) to (ii). On what basis then do we cling to the view that it would be impossible for an animal to commit suicide or engage in suicidal behavior?

${ }^{20}$ Animals are used in pharmacological studies of intra-cranial self-stimulation, in sensory manipulation experiments that explore the links between serotonin and noradrenaline and between corticosteroids and stress (e.g., olfactory bulbectomy tests), in behavioral experiments on hopelessness, fatigue, and chronic stress (e.g., forced swimming tests), and in social-stress tests involving "disrupted parenting" and "disrupted social hierarchies" (e.g., social isolation tests). See Preti (2011). 
Perhaps the answer is that an interpretative bias has permeated the fields of animal and suicide research: the bias of humanism. From an early age, we are taught that human beings stand over and above all other animals by virtue of possessing a special "something" (reason, language, subjectivity, free will, awareness of death, or something else) that gives us an exceptional and inimitable moral status. This belief affects how we think and talk about animals, not to mention how we treat them. It may also affect how we interpret data about the richness and complexity of their cognitive, behavioral, and social lives. In may cause us, for example, to apply atypical standards of evidence in some settings but not others and to dismiss from the outset hypotheses that we are already psychologically predisposed to doubt or reject (Leavens, Bard, and Hopkins 2017; Willett 2014; Burghardt 2016). One could argue that in the case of the animal sciences, this bias manifests itself primarily as an anticonfirmation bias that inclines us to be hyper-skeptical of ideas that challenge our belief in our presumed uniqueness and superiority. In our minds, such ideas never get confirmed no matter how much support they might have.

This bias puts suicide researchers in a double bind since they must take a position on whether the link between negative emotions and self-destructive behaviors exists in both humans and nonhuman animals. If they accept the link, they safeguard the validity of animal models in suicide research but undermine the ideology of human exceptionalism that posits a break between humans and animals. If they reject it, they safeguard the ideology of human exceptionalism but call into question the legitimacy of animal-based suicide research itself. Either way, something must give. If animals can self-destruct because of negative emotions and psychopathologies, we may be (epistemologically, not necessarily ethically) justified in using them as models for human suicide. But then we cannot rule out the possibility that they, too, commit suicide. If, by contrast, they cannot, we may rule out the possibility of animal suicide, but we must end our use of animal models since they cannot "advance our knowledge regarding suicide" (Rezaeian 2012, p. 17). Our belief that animals cannot engage in suicidal behavior and our belief that animal-based research can illuminate "every single step leading to suicide in humans" (Preti 2011a, p. 821) may be incompatible.

\section{The Animal Suicide Hypothesis: A Continuist Approach}

Thinking about self-destructive behaviors as points on a spectrum that includes humans and animals opens the door to a new way of thinking about suicide that foregrounds suicidal behavior. On this view, which we may call "the continuist view," suicidal behavior is a natural spectrum that encompasses a wide range of animal activities that are (i) selfdirected and that (ii) result in serious injury to the animal or in the termination of its lifeactivity either suddenly or over an extended period of time. At one end of this spectrum, we find some of the most sophisticated acts of self-annihilation of cognitively complex animals, humans included; at the other end, we find more basic forms of self-injury and selfdestruction, such as the self-sting of the scorpion. Strewn between these extremes, we find a plethora of "middle cases" that are related to one another by degree. This view treats selfdestructive behaviors as expressions of what Goldney (1980) calls "conservationwithdrawal," which is the complex and multiply-realizable process whereby an animal deactivates or negates its normal life-conserving activities.

Two dimensions of this theory require elaboration. First, notice that this theory admits no radical gap between the human and the nonhuman. It rejects the popular notion 
that "something" makes us, homo sapiens, biologically unique. Importantly, this does not rule out meaningful differences between different types of suicidal behaviors or between the kinds of suicidal behaviors that are possible for different species. Just as Darwin's insight that humans and animals exist on an evolutionary continuum has not kept natural scientists from successfully telling a human apart from a rhesus monkey, nothing internal to the continuist paradigm requires that we view all suicidal behaviors as "the same." All the continuist view holds is that there is no "something" that makes suicidal behavior a possibility only for humans. Suicidal behavior is multiply realizable, and this means that it can be effectuated by different causal pathways and can take radically different forms that will likely vary depending on a number of factors, such as the evolutionary lineages of different species, the developmental histories of different animals, the means of self-destruction at their disposal, the presence or absence of different psychopathologies, and so on.

Second, and more controversially, the continuist theory does away with the classical notion that intent always precedes behavior and must be a component of all suicideexplanations. Many commentators will no doubt look askance at a theory of suicide that relinquishes the concept of intent since "it is a near-universal premise in contemporary cognitive sciences that mental states cause behavior" (Leavens, Bard, and Hopkins 2017, p. 6). Yet there are good reasons to be suspicious of this "near-universal" belief, which is already losing ground in the animal sciences in light of recent work on animal cognition that explains animal behavior without recourse to mental states, including intentions.

Consider Leavens et al.'s (2017) recent work on ape social cognition and communication. Many primatologists have claimed that apes do not engage in declarative or expressive gestures (such as pointing) because they cannot conjure up the requisite mental states to do so - that is, because they cannot intend the right thing in the right way. This view, which has shaped virtually all research on ape cognition since at least the 1970s, relies "on the core assumption that intentional and epistemic states cause overt behavior" (Leavens et al. 2017, p. 6). In the absence of epistemic states, behavior cannot materialize.

Leavens et al., however, attack this view from three different angles. First, they point out that this "core assumption" is unnecessary, as there are plenty of models of behavior that do not hypostatize mental states (beliefs, intentions, desires) as causes of expressed behavior. In the study of human behavior, such models include "theoretical positions grounded in distributed or embodied cognitive perspectives [...] and also some recent extensions of behaviorism" (ibid.). ${ }^{21}$ In the study of animal behavior, this includes experimental approaches based on "cross-fostering," "radical operationalization," "training," and "sampling," all of which the authors advocate (ibid. pp. 5-12).

Leavens et al. also point out that the hypothesis that mental states cause behavior is empirically bankrupt. Although we are accustomed to thinking that mental states cause behavior, "it is, in practice, impossible to assign a truth value to the presence or absence of any hypothetical mental state" (ibid. p. 7). At present, there is no scientific procedure - no fMRI, no questionnaire, no surgical intervention - that can detect the presence or absence of a mental state in a person, let alone track or measure it in a scientifically meaningful way. "This may not be immediately obvious to some readers," they write, but appealing to mental

${ }^{21}$ Examples of the embodied-cognition approach include Barrett (2011); Chemero (2011); Johnson (2001); Sehon (2000); and Varela, Thompson, and Rosch (1991): examples of the neo-behaviorist approach include Rachlin (1992) and Baum (2002). Both approaches explain behavior without appealing to intentions. 
states in scientific articles is, technically, no different from appealing to "demons, or angels, or spirits, or what have you" (pp. 10-11). Like "angels" and "demons," "mental states" are "structurally unfalsifiable" and consequently empirically meaningless (ibid.; Popper 2005). The mental model of behavior, therefore, cannot demonstrate the presence or absence of intentions "in any species, including humans," or even prove that behavior is causally dependent upon mental states (ibid.). It merely posits as objectively real a set of causes (mental states) that no scientific procedure can either confirm or falsify.

Leavens et al. round off their appraisal of the mental model of behavior by presenting empirical evidence that apes do engage in gestural behaviors similar to those of human children. Of course, we cannot access the ape mind to see whether these creatures intend to share information about the location of an object when they index it, but the point is that we needn't because appeals to intentions are not necessary for the scientific explanation of behavior and may, in fact, undermine it. The authors concede that none of the alternative approaches they discuss - such as alternatives rooted in embodied cognition or neobehaviorism - will ever "reveal hypothetical psychological causal factors," but this incapacity is already inherent "in all contemporary approaches to comparative and developmental social cognition" since such factors are necessarily inaccessible to empirical researchers (ibid., p. 13). Given the logical and empirical inadequacies of the mental model, they conclude, we should move "beyond unfalsifiable psychologies of communication" (ibid., p. 11); and the first step in that direction is to stop explaining behavior via intent.

We should apply Leavens et al.'s critique of the use of mental states in discussions of social cognition to contemporary discussions of suicide because there are real cases in which intent appears either at the same time as (in actu) or even after (ex-post facto) the behavior it supposedly causes, ${ }^{22}$ and suicide may be among them. Durkheim (2002) argues that intent is not a necessary condition for human suicide. ${ }^{23}$ Meanwhile, Jones (1982) invites us to view suicide as a complex chain of events in which suicidal behavior comes first and suicidal intent second. For him, the intent to die, if it forms at all, often forms after the process of conservation-withdrawal has begun. Contemporary theories of suicide that latch onto the concept of intent may therefore inadvertently limit their own explanatory scope and theoretical appeal by universalizing a framework that is already suspect in the cognitive and animal sciences and whose organizing principle may be a serious conceptual liability.

The scientific study of suicide is likely to benefit from capitalizing on the image of suicide as a continuum of conservation-withdrawal behaviors. This image fits better with the latest empirical findings about the behavioral and cognitive abilities of many animals and does not render the entire field of human suicide research epistemologically suspect by

\footnotetext{
${ }^{22}$ Apart from the theories mentioned by Leavens, Bard, and Hopkins (2017), there are many others that do not require intent to precede behavior. Maurice Merleau-Ponty's theory of embodied cognition holds that motivation need not precede action because intent is often constructed in actu (Merleau-Ponty 1964, p. 19; Merleau-Ponty 2012, p. 505). Searle's (1983) theory of mind also uses the concept of "intention-in-action" to capture actions that are contemporaneous with the intent that presumably "explains" them. Libet's (1999) psychological experiments on volitional acts and unconscious motivation suggest that actions may initiate before one becomes aware of them and thus before one can properly intend them (Libet et al. 1999). Rowlands (2006) has developed an account of the normativity of action that deflates the role of mental representation and intentionality.

${ }^{23}$ Durkheim (2002) argues that not all suicides involve the conscious intent to die (e.g., soldiers who sacrifice themselves for their regiment, martyrs who die for their faith, and mothers who sacrifice themselves for their child). With or without intent, he says, all suicides remain "varieties of a single class" (p. xli).
} 
mystifying the "cross-species parallels" it presupposes (Malkesman et al. 2009). Moreover, it is tidier and neater as an explanatory framework than its anthropocentric counterpart. Depending on how it is formulated, the anthropocentric theory that only humans commit suicide fails to explain various human suicides. When it requires reflexive subjectivity, it fails to explain the suicides of humans who may not meet certain criteria of self-cognizance, such as children and individuals with severe cognitive disabilities. When it requires free will, it fails to explain human suicides triggered by empirically tractable natural causes (such as antidepressants). When it requires awareness of death, it once again runs into the problem of children and the severely cognitively disabled who, at least on some interpretations, may not understand their own mortality or that of others. ${ }^{24}$ Finally, when it requires intent, the anthropocentric theory faces the empirical problem that intent is unfalsifiable, the causal problem that it may not precede behavior, and the epistemological problem that (even if it exists and precedes behavior) it may be impossible to ascertain, especially postmortem..$^{25}$ Continuism remedies these weaknesses.

\section{Epistemic Humility}

"Epistemic humility" refers to an attitude of openness and modesty relative to one's own beliefs. ${ }^{26}$ Especially under conditions of uncertainty, epistemic humility can be a scholarly virtue of sorts. To be humble in an epistemic sense means to be candid about the limits of scientific knowledge - to recognize the gaps, rifts, and lacunae that often inhere in even our most powerful theories (and to calibrate our beliefs about the world accordingly). It means remaining open to possibilities that are consistent with the observational and theoretical scaffolding of a science even if they cut against the grain of received wisdom or personal conviction. To be epistemically humble is to be modest about the strength and reach of our ways of seeing and interpreting the world. Applied to animal suicide, epistemic humility requires taking seriously the empirical evidence that challenges our preconceived ideas about the cognitive, emotional, and behavioral capabilities of nonhuman animals, and facing up to the empirical and conceptual shortcomings of the anthropocentric theory of suicide.

Some experts on animal behavior already embrace a continuist interpretation of suicide (Crawley, Sutton, and Pickar 1985, p. 308; Braitman 2014, p. 210). Still, opponents often rebuff them by pointing out that we have not yet created a successful animal model of suicide (Comai and Gobbi 2016; Hooper 2010). This, they argue, proves that animals are incapable of suicidal behavior. As Comai and Gobbi (2016) put it: "there are no animal models of suicide mainly because there is no instance of suicide among animals" (p. 177). But aside from begging the question, this argument ignores numerous alternative explanations for the nonexistence of these models (see Table 3). Whereas it is true that animal suicide has not yet

\footnotetext{
${ }^{24}$ McEvoy, Reid, and Guerin (2002); and McEvoy, MacHale, and Tierney (2012), reject this view.

${ }^{25}$ Already in the nineteenth century, the Italian psychiatrist Enrico Morselli hypothesized that many suicidal agents may be unaware of why they killed themselves. The reason for their suicide eludes them (Ramsden and Wilson 2014). Durkheim (2002) echoed this view: "Intent is too intimate a thing to be more than approximately interpreted by another. It even escapes self-observation. How often we mistake the true reasons for our acts! We constantly explain acts due to petty feelings or blind routine by generous passions or lofty considerations" (p. xli).

${ }^{26}$ I borrow the concept of epistemic humility from Schwab (2012), who advocates its use in medicine.
} 
been modeled in a laboratory, epistemic humility dictates that it cannot be ruled out altogether on the basis of current knowledge.

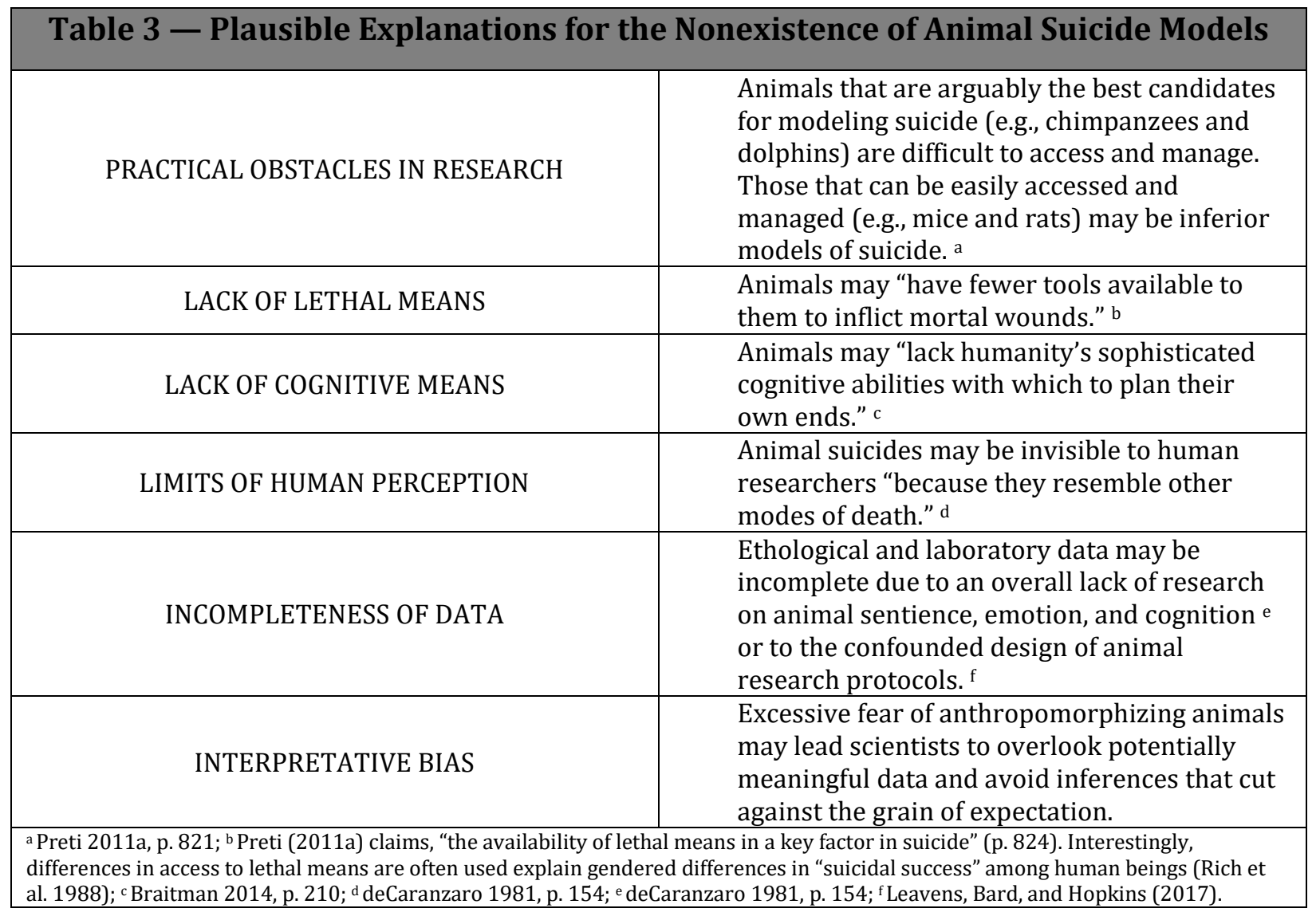

There are epistemological and ethical reasons to adopt an attitude of epistemic humility in debates about animal suicide. Epistemologically, this attitude helps us avoid rash conclusions about animals that may clash with the empirical findings of the cognitive and behavioral sciences. Ethically, it is the least likely to contribute, directly or indirectly, to the harming of animals. Willett (2014) holds that scientific judgments about what animals can and cannot do often motivate non-scientific judgments about what humans can and cannot do to them. The less we think animals are capable of, the more we rationalize "intrumentalizing" them and causing them harm for human benefit (in laboratories, factories, farms, etc.). Judgments about animal suicide, then, are not only scientific; they are ethical, too. And from an ethical standpoint, an attitude of epistemic humility is preferable because it best satisfies what philosophers call the "minimax principle" of rationality, which holds that when choosing between two options, one should choose the one most likely to yield the best worstcase scenario.

If animals can commit suicide and the animal suicide hypothesis is correct, epistemic humility helps us avoid (a) the epistemic loss of making false inferences about nonhuman animals and (b) the ethical risk that those inferences will be used to justify the unethical treatment of animals. But if animals really are incapable of committing suicide and the animal suicide hypothesis is wrong, epistemic humility incurs (a) no ethical costs and (b) only the negligible epistemic cost of having delayed the acceptance of this correct inference. Ethical 
cost-benefit analysis tips the balance in favor of the continuist view. [Cf. Birch's (2017) target article and commentaries on the Precautionary Principle in this journal - ed.]

\section{Implications}

The hypothesis of animal suicide upsets our cultural beliefs about animals and, if true, may have significant practical and ethical implications. In their work on chimpanzee mourning, for instance, Anderson, Gillies, and Lock (2010), argue that if we accept that chimpanzees have a concept of death, we may incur a number of ethical responsibilities toward them that should affect how we treat and manage them in zoos, sanctuaries, and laboratories. ${ }^{27}$ For them, the scientific debate on whether chimpanzees have a concept of death has implications beyond science.

A similar argument may be made about suicide. If we grant that animals engage in suicidal behavior, a number of things may follow. Perhaps it follows that veterinarians should be better trained in the diagnosis and management of suicidal behaviors in animals. Perhaps it follows that animal researchers should invest more time and energy into studying how suicidal behavior manifests in different species and under different environmental conditions. Perhaps it also follows that if certain animals are shown by future research to be statistically more likely to self-destruct in certain environments, we may have a moral duty to change those environments or relocate the animals. If animals, commit suicide while under human care, we may have to apply a strict scrutiny standard to those responsible for them.

More generally, it may also follow that all of us should engage in serious self-critique and rethink our assumptions about animals (and alter our practices accordingly). For example, if some animals engage in suicidal behavior, does this mean they engage in the kind of "negation behavior" that anthropologists have historically hailed as the Promethean dimension of human life? Does this mean that they, as Fenton (2014) argues using chimpanzees as examples, have the ability to say "no" - "no" to other animals, "no" to humans, "no" perhaps to life itself? Can animals reflect on, and reject, their conditions of existence? Can a chimp, mirroring Socrates, differentiate between a "life" and "life worth living"?28 These may sound like just abstract philosophical questions, but they have concrete ramifications for researchers, veterinarians, and even ethicists that we cannot ignore. Ethically, what might it mean that captivity drives some animals to the edge of selfannihilation? Similarly, what might it mean that we often use sentient beings that may be capable of consent in invasive biomedical research without their consent (whatever that may look like)? That's the thing about philosophical questions - they seem distant, until they hit

\footnotetext{
${ }^{27}$ After observing how a group of chimpanzees at Blair Drummond Safari Park in Scotland dealt with the death of a conspecific, Anderson, Gillies, and Lock (2010) concluded that chimpanzees prefer not to die in isolation. For chimpanzees, a good death, much like a good life, is one shared in communion with others. As a result, we may be ethically obliged to study how chimpanzees normally deal with death in the wild so as to avoid placing them in situations where they are unable to cope with it in species-typical ways while in captivity. We may also be morally obliged to ensure that, if they die under our care, they do so with dignity. And we may be obliged to avoid euthanizing these animals, even if we think this is the compassionate thing to do: "It might be more humane to allow elderly apes to die naturally in their familiar social setting than to attempt to separate them for treatment or euthanasia" (p. R351).

${ }^{28} \mathrm{Hribal}$ (2007) claims animals can, and do, refuse to live under conditions they find deplorable.
} 
home.

\section{Conclusion}

There are sound empirical and philosophical reasons to support the animal suicide hypothesis. Some follow from ethological and laboratory research about animal sentience, cognition, and behavior: others from what current suicide research practices entail. A "paradigm shift" (Kuhn 1970) in suicide research from a mentalistic and anthropocentric to a more behaviorist and continuist approach could deepen our understanding of the parallels between human and nonhuman animals and help solve various conceptual problems in human suicide research. It would also put pressure on suicide researchers to define suicide more clearly, and on animal researchers to better justify the grounds on which they postulate some "great divide" between humans and animals. If such a divide exists, suicide is not it.

Although stories about suicidal animals are anecdotal, what matters is that they are perfectly plausible from the standpoint of contemporary science (Preti 2011a, p. 819). Thus, even if we cannot currently prove that any animal has committed suicide as a matter of fact, there is a large and growing body of evidence indicating that this possibility cannot be ruled out as a matter of principle. Some creatures, to quote Braitman (2014), "should be given the benefit of the doubt" (p. 159). Given the stakes, we owe animals at least that much.

\section{Glossary}

ANHEDONIA: The inability to experience states of pleasure and joy.

ANTHROPOCENTRIC THEORY OF SUICIDE: The view that only human beings are capable of engaging in suicidal behavior and completion.

CONTINUIST THEORY OF SUICIDE: The view that the suicidal behaviors of human and nonhuman animals exist on a natural continuum.

EPISTEMIC HUMILITY: The virtue of being modest in one's judgments about the social, cognitive, and behavioral capacities of nonhuman animals.

FREE WILL: A metaphysical force that allows individuals to make choices that are not caused or determined by prior natural causes.

HUMANIST BIAS: An error in interpreting and evaluating information that occurs as a result of holding onto the belief that humans are exceptional among, and superior to, the animals.

INTENT: A mental state typically believed to cause the behavior of rational, linguistic agents.

SENTIENCE: The ability "to experience pleasurable states such as joy, and aversive states such as pain and fear" (Helen 2012, p. 628). 
SUICIDAL BEHAVIOR: Self-directed acts that can endanger the wellbeing of an animal or terminate its life-activity.

SUICIDE: Suicidal behavior that culminates in the death of an animal; see "suicidal behavior."

Acknowledgements: I would like to thank G.K.D. Crozier for reading an early version of this paper at the 2016 meeting of the Canadian Society for Bioethics in my absence and for giving feedback on an early draft, Andrew Fenton and Letitia Meynell for our ongoing conversations about animal ethics, and Cynthia Willett for her mentorship and influence. I would also like to thank the five Animal Sentience reviewers and Rabih Hage for their extremely challenging but helpful feedback, as well as Stevan Harnad for his editorial help and support in the preparation of this manuscript.

Call for Commentary: Animal Sentience publishes Open Peer Commentary on all accepted target articles. Target articles are peer-reviewed. Commentaries are editorially reviewed. There are submitted commentaries as well as invited commentaries. Commentaries appear as soon as they have been reviewed, revised and accepted. Target article authors may respond to their commentaries individually or in a joint response to multiple commentaries.

Instructions: http://animalstudiesrepository.org/animsent/guidelines.html

\section{References}

Anderson, J.R., Gillies, A., \& Lock, L.C. (2010). Pan thanatology. Current Biology, 20, R349R351.

Angier, N. (2008). Do animals grieve over death like we do? The New York Times. September 2.

Baars, B.J. (2005). Subjective experience is probably not limited to humans: The evidence from neurobiology and behavior. Consciousness and Cognition, 14, 7-21.

Barrett, L. (2011). Beyond the brain: How body and environment shape animal and human minds. Princeton, NJ: Princeton University Press.

Baum, W.M. (2002). From molecular to molar: A paradigm shift in behavior analysis. Journal of the Experimental Analysis of Behavior, 78, 95-116.

BBC News. (2015). The birds that fear death.

Beauchamp, T.L., \& Childress, J. F. (1978). Principles of biomedical ethics. Oxford, UK: Oxford University Press. 
Bekoff, M. (2007). The emotional lives of animals. Novato, CA: New World Library.

Bekoff, M. (2009a). Animal emotions, wild justice and why they matter: Grieving magpies, a pissy baboon, and empathic elephants. Emotion, Space and Society, 2, 82-85.

Bekoff, M. (2009b). A fox, a cougar, and a funeral: Foxes and other animals grieve the loss of others. Psychology Today, July 22.

Bekoff, M., \& Sherman, P. (2004). Reflections on animal selves. TRENDS in Ecology and Evolution, 19, 176-180.

Benvenuti, A. (2016). Evolutionary continuity and personhood: Legal and therapeutic implications of animal consciousness and human unconsciousness. International Journal of Law and Psychiatry, 48, 43-49.

Berns, G.S., Brooks, A.M., \& Spivak, M. (2012). Functional MRI in awake unrestrained dogs. Plos ONE, 7, 1-7.

Birch, J. (2017). Animal sentience and the precautionary principle. Animal Sentience 16(1).

Biro, D., Humle, T., Koops, K., Sousa, C., Hayashi, M., \& Matsuzawa, T. (2010). Chimpanzee mothers at Bossou, Guinea carry the mummified remains of their dead infants. Current Biology, 20, R351-R352.

Bodzy, M.E., Barreto, S.J., Swenson, L.P., Liguori, G., \& Costea, G. (2016). Self-reported psychopathology, trauma symptoms, and emotion coping among child suicide attempters and ideators: An exploratory study of young children. Archives of Suicide Research, 20, 160-175.

Bradshaw, G.A., Schore, A.N., Brown, J.L., Poole, J.H., \& Moss, C.J. (2005). Elephant breakdown. Nature, 433, 807.

Braitman, L. (2014). Animal madness: How anxious dogs, compulsive parrots, and elephants in recovery help us understand ourselves. New York, NY: Simon and Schuster.

Bruene, M., Bruene-Cohrs, U., McGrew, W.C., \& Preuschoft, S. (2006). Psychopathology in great apes: Concepts, treatment options and possible homologies to human psychiatric disorders. Neuroscience \& Biobehavioral Reviews, 30, 1246-1259.

Burghardt, G. (2016). Mediating claims through critical anthropomorphism. Animal Sentience $3(17)$.

Camus, A. (1955). The myth of Sisyphus and other essays. New York, NY: Alred A. Knopf. Chemero, A. (2011). Radical embodied cognitive science. Cambridge, MA: MIT Press.

Cheung, G., Merry, S., \& Sundram, F. (2015). Late-life suicide: Insight on motives and contributors derived from suicide notes. Journal of Affective Disorders, 185, 17-23.

Comai, S., \& Gobbi, G. (2016). Translational research in suicide: is it possible to study in animal models? In Understanding suicide: From diagnosis to personalized treatment, ed. P. Courtet, 177-190.

Conlee, K.M., \& Rowan, A.N. (2012). The case for phasing out experiments on primates. Hastings Center Report, 42, 1.

Crawley, J.N., Sutton, M.E., \& Pickar, D. (1985). Animal models of self-destructive behavior and suicide. Psychiatric Clinics of North America, 8, 299-310.

deCatanzaro, D. (1981). Suicide and self-damaging behavior: A sociobiological perspective. New York, NY: Academic Press.

DeGrazia, D. (1996). Taking animals seriously: mental life and moral status. Cambridge, MA: Cambridge University Press.

DeGrazia, D. (2006). On the question of personhood beyond Homo sapiens. In Defense of animals: The second wave, ed. Singer, P. Hoboken, NJ: Blackwell Publishing, 40-53. 
DeGrazia, D. (2016). Nonhuman primates, human need, and ethical constraints. Hastings Center Report, 46, 27-28.

DeGrazia, D., \& Sebo, J. (2015). Necessary conditions for morally responsible animal research. Cambridge Quarterly of Healthcare Ethics, 24, 420-430.

Douglas, J.D. (2015). Social meanings of suicide. Princeton, NJ: Princeton University Press.

Durkheim, E. (2002). Suicide: A study in sociology. (Reprint). New York, NY: Routledge.

Ebert, J.P., \& Wegner, D.M. (2011). Mistaking randomness for free will. Consciousness and Cognition, 20, 965-971.

Feinberg, T.E., \& Mallatt, J. (2013). The evolutionary and genetic origins of consciousness in the Cambrian Period over 500 million years ago. Frontiers in Psychology, 4, 667.

Fenton, A. (2012). On the need to redress an inadequacy in animal welfare science: Toward an internally coherent framework. Biology \& Philosophy, 27, 73-93.

Fenton, A. (2014). Can a chimp say 'no'? Cambridge Quarterly of Healthcare Ethics, 23, 130139.

Gallup, G.G. (1970). Chimpanzees: Self recognition. Science, 167, 86-87.

Goldman, J. (2012). Death rituals in the animal kingdom. BBC News. September 19.

Goldney, R.D. (1980). Attempted suicide: an ethological perspective. Suicide and LifeThreatening Behavior, 10, 131-141.

Gould, T.D., Georgiou, P., Brenner, L.A., Brundin, L., Can, A., Courtet, P., Donaldson, Z.R., Dwivedi, Y., Guillaume, S., Gottesman, I., Kanekar, S., Lowry, C.A., Renshaw, P.F., Rujescu, D., Smith, E.G., Turecki, G., Zanos, P., Zarate, C.A., Zunszain, P.A., \& Postolache, T.T. (2017). Animal models to improve our understanding and treatment of suicidal behavior. Translational Psychiatry, 7, e1092.

Hassana, R. (1998). One hundred years of Emile Durkheim's Suicide: A study in sociology. Australian and New Zealand Journal of Psychiatry, 32, 168-171.

Heise, B., York, A., \& Thatcher, B. (2016). Child suicide screening methods: Are we asking the right questions? A review of the literature and recommendations for practice. The Journal for Nurse Practitioners, 12, 410-417.

Higonnet, M. (1986). Speaking silences: Women's suicide. In The female body in western culture: Contemporary perspectives, ed. Suleiman, R. Cambridge, MA: Harvard University Press, 68-83.

Hooper, R. (2010). Animals do not commit suicide. New Scientist. March 4.

Hribal, J. (2007). Animals, agency, and class: Writing the history of animals from below.

Human Ecology Review, 14, 101-112.

James, W. (1995). Pragmatism. Dover Publications.

Johnson, C.M. (2001). Distributed primate cognition: A review. Animal Cognition, 3, 167-183.

Jones, I. (1982). Self-injury: Toward a biological basis. Perspectives in Biology and Medicine, $26,137-150$.

King, B.J. (2013). How animals grieve. Chicago, IL: University of Chicago Press.

King, B.J. (2016). Animal mourning: Précis of How animals grieve (King 2013). Animal Sentience 4(1).

Korte, S.M., Olivier, B., \& Koolhaas, J.M. (2007). A new animal welfare concept based on allostasis. Physiology \& Behavior, 92, 422-428.

Kuhn, T.S. (1970). The structure of scientific revolutions. Chicago, IL: University of Chicago Press. 
Lahvis, G.P. (2017). Social reward and empathy as proximal contributions to altruism: The camaraderie effect. Current Topics in Behavioral Neurosciences, 30, 127-157.

Latzman, R.D., Drislane, L.E., Hecht, L.K., Brislin, S.J., Patrick, C.J., Lilienfeld, S.O., Freeman, H.J., Schapiro, S.J. \& Hopkins, W.D. (2016). A chimpanzee (pan troglodytes) model of triarchic psychopathy constructs: Development and initial validation. Clinical Psychological Science, 4, 50-66.

Leavens, D.A., Bard, K.A., \& Hopkins, W.D. (2017). The mismeasure of ape social cognition. Animal Cognition, 1-18.

Libet, B., Freeman, A., \& Sutherland, K. (1999). The volitional brain. Toward a neuroscience of free will. Thorverton, UK: Imprint Academic.

Lilienfeld, S.O., Gershon, J., Duke, M., Marino, L., \& de Waal, F.B. (1999). A preliminary investigation of psychopathic personality (psychopathy) in chimpanzees (Pan troglodytes). Journal of Comparative Psychology, 113, 365-375.

Lipska, B.K., \& Weinberger, D.R. (2000). To model a psychiatric disorder in animals: Schizophrenia as a reality test. Neuropsychopharmacology, 23, 223-239.

Mackie, J. (1955). Evil and omnipotence. Mind, 64, 200-212.

Malkesman, O., Pine, D.S., Tragon, T., Austin, D.R., Henter, I.D., Chen, G., \& Manji, H.K. (2009). Animal models of suicide-trait-related behaviors. Trends in Pharmacological Sciences, 30, 165-173.

Marino, L. (2016). "Suicide in Dolphins: A Possibility? (White Paper)." Personal communication, July 9.

Martin, G. (2014). Editorial: On child suicide. Advances in Mental Health, 12, 88-92.

Matsuzawa, T. (1997). The death of an infant chimpanzee at Bossou, Guinea. Pan Africa News, 4, 4-6.

Matsuzawa, T. (2006). Sociocognitive development in chimpanzees: A synthesis of laboratory work and fieldwork. In Cognitive Development in Chimpanzees. Tokyo, Japan: Springer, 3-33.

Matter, D.E., \& Matter, R.M. (1984). Suicide among elementary school children: A serious concern for counselors. Elementary School Guidance \& Counseling, 18, 260-267.

McCain, J.A. (2009). Antidepressants and suicide in adolescents and adults: A public health experiment with unintended consequences. Pharmacy and Therapeutics, 34, 355-367.

McEvoy, J., MacHale, R., \& Tierney, E. (2012). Concept of death and perceptions of bereavement in adults with intellectual disabilities. Journal of Intellectual Disability Research, 56, 191-203.

McEvoy, J., Reid, Y., \& Guerin, S. (2002). Emotion recognition and concept of death in people with learning disabilities. The British Journal of Development Disabilities, 48, 83-89.

Mercado, III, E., Murray, S.O., Uyeyama, R.K., Pack, A.A., \& Herman, L.M. (1998). Memory for recent actions in the bottlenosed dolphin (Tursiops truncatus): Repetition of arbitrary behaviors using an abstract rule. Animal Learning and Behavior, 26, 210-218.

Mercado, III, E., Uyeyama, R.K., Pack, A.A., \& Herman, L.M. (1999). Memory for action events in the bottlenosed dolphin. Animal Cognition, 2, 17-25.

Merleau-Ponty, M. (1964). Sense and non-sense. Evanston, IL: Northwestern University Press.

Merleau-Ponty, M. (2012). Phenomenology of perception. London, UK: Routledge. Morin, R. (2015). A conversation with Koko the gorilla. The Atlantic, August 15. Nobel, J. (2010). Do animals commit suicide? A scientific debate. Time, March 19. 
NOVA. (2008). Ape Genius, DVD, directed by John Rubin. National Geographic Television.

O’Connor, L.E., Berry, J.W., Landau, V., King, J., Pederson, A., Weiss, A., \& Silver, D. (2001).

Chimpanzee pychopathology and subjective wellbeing and social adjustment. In ChimpanZoo 2000 conference proceedings. ChimpanZoo: Research, Education and Enrichment Program, 24-32.

Overall, K.L. (2000). Natural animal models of human psychiatric conditions: Assessment of mechanism and validity. Progress in Neuro-Psychopharmacology and Biological Psychiatry, 24, 727-776.

Palmer, J. (2010). Free will similar in animals, humans-but not so free. BBC News, December 16. Available at: www.bbc.com/news/science-environment-11998687

Patrick, C.J. (2010). Operationalizing the triarchic conceptualization of psychopathy: Preliminary description of brief scales for assessment of boldness, meanness, and disinhibition. Unpublished test manual, Florida State University.

Patrick, C.J., Fowles, D. C., \& Krueger, R. F. (2009). Triarchic conceptualization of psychopathy: Developmental origins of disinhibition, boldness, and meanness. Development and Psychopathology, 21, 913-938.

Perlin, S. (1994). A handbook for the understanding of suicide. Northvale, NJ: Jason Aronson. Popper, K. (2005). The logic of scientific discovery. New York, NY: Routledge.

Preti, A. (2007). Suicide among animals: A review of evidence. Psychological Reports, 101, 831-848.

Preti, A. (2011a). Animal model and neurobiology of suicide. Progress in NeuroPsychopharmacology and Biological Psychiatry, 35, 818-830.

Preti, A. (2011b). Do animals commit suicide? does it matter? Crisis, 32, 1-4.

Prior, H., Schwarz, A., \& Güntürkün, O. (2008). Mirror-induced behavior in the magpie (Pica pica): Evidence of self-recognition. PLoS Biology, 6, 1642-1650.

Rachlin, H. (1992). Teleological behaviorism. American Psychologist, 47, 1371-1382.

Ramsden, E., \& Wilson, D. (2014). The suicidal animal: Science and the nature of selfdestruction. Past \& Present, 224, 201-242.

Reggente, M.A., Alves, F., Nicolau, C., Freitas, L., Cagnazzi, D., Baird, R.W., \& Galli, P. (2016). Nurturant behavior toward dead conspecifics in free-ranging mammals: New records for odontocetes and a general review. Journal of Mammalogy, 97, 1428-1434.

Reiss, D., \& Marino, L. (2001). Self-recognition in the bottlenose dolphin: A case of cognitive convergence. Proceedings of the National Academy of Sciences USA, 98, 5937-5942.

Rezaeian, M. (2012). Methodological issues and their impacts on suicide studies. Middle East Journal of Business, 7, 17-19.

Rich, C.L., Ricketts, J.E., Fowler, R.C., \& Young, D. (1988). Some differences between men and women who commit suicide. American Journal of Psychiatry, 145, 718-722.

Rowlands, M. (2006). The normativity of action. Philosophical Psychology, 19, 401-416.

Rowlands, M. (2016). Are animals persons? Animal Sentience 10(1).

Schwab, A. (2012). Epistemic humility and medical practice: Translating epistemic categories into ethical obligations. Journal of Medicine and Philosophy, 37, 28-48.

Searle, J. (1983). Intentionality: An essay in the philosophy of mind. New York, NY: Cambridge University Press.

Sehon, S.R. (2000). An argument against the causal theory of action explanation. Philosophy and Phenomenological Research, 60, 67-85.

Seligman, M.E. (1972). Learned helplessness. Annual Review of Medicine, 23, 407-412. 
Seth, A.K., Baars, B.J., \& Edelman, D.B. (2005). Criteria for consciousness in humans and other mammals. Consciousness and Cognition, 14, 119-139.

Shneidman, E. (1985). Definition of suicide. New York, NY: Wiley.

Stefanowski-Harding, S. (1990). Child suicide: A review of the literature and implications for school counselors. The School Counselor, 37, 328-336.

Steward, H. (2015). Do animals have free will? The Philosophers' Magazine, 68, 43-48.

Szasz, T. (1986). The case against suicide prevention. American Psychologist 41, 806-812.

Tan, J., \& Hare, B. (2013). Bonobos share with strangers. Plos ONE, 8, 1-11.

Tononi, G., \& Koch, C. (2015). Consciousness: Here, there and everywhere?. Philosophical Transactions of the Royal Society $B, 370,1-18$.

Varela, F.J., Thompson, E., \& Rosch, E. (2017). The embodied mind: Cognitive science and human experience. Cambridge, MA: MIT Press.

Varki, A., \& Brower, D. (2013). Denial: Self-deception, false beliefs, and the origins of the human mind. New York, NY: Hachette Book Group.

Walker, J.K., Waran, N.K., \& Phillips, C.J. (2016). Owners' perceptions of their animal's behavioural response to the loss of an animal companion. Animals, 6, 68-82.

Wedderburn, P. (2015). Animals grieve just as people do. The Telegraph, January 10.

Wegner, D.M. (2003). The mind's best trick: How we experience conscious will. Trends in Cognitive Sciences, 7, 65-69.

Wegner, D.M. (2004). Précis of the illusion of conscious will. Behavioral and Brain Sciences, $27,649-659$.

Willett, C. (2014). Interspecies ethics. New York, NY: Columbia University Press.

Windt, P. (1981). The concept of suicide. In Suicide: The philosophical issues, eds. Battin, M.P., \& Mayo, D.J. New York, NY: St. Martin's Press, 82-97.

Yang, B., Anderson, J.R., \& Li, B.G. (2016). Tending a dying adult in a wild multi-level primate society. Current Biology, 26, R403-R404. 


École d'été
en sciences
cognitives 2018
26 juin - 6 juillet
$\begin{aligned} & \text { Summer School } \\ & \text { in cognitive } \\ & \text { sciences } 2018 \\ & \text { June } 26^{\text {th }} \text { - July } 6^{\text {th }}\end{aligned}$
UQĀM $\mid$ ISC
Institut des sciences cognitives

\author{
ISC 2018 Summer School \\ in Cognitive Sciences \\ June 26 - July 6, 2018 \\ Montreal (Canada) \\ The Other Minds \\ Problem: Animal \\ Sentience and Cognition
}

Overview. Since Descartes, philosophers know there is no way to know for sure what — or whether — others feel (not even if they tell you). Science, however, is not about certainty but about probability and evidence. The 7.5 billion individual members of the human species can tell us what they are feeling. But there are 9 million other species on the planet (20 quintillion individuals), from elephants to jellyfish, with which humans share biological and cognitive ancestry, but not one other species can speak: Which of them can feel — and what do they feel? Their human spokespersons - the comparative psychologists, ethologists, evolutionists, and cognitive neurobiologists who are the world's leading experts in "mindreading" other species - will provide a sweeping panorama of what it feels like to be an elephant, ape, whale, cow, pig, dog, chicken, bat, fish, lizard, lobster, snail: This growing body of facts about nonhuman sentience has profound implications not only for our understanding of human cognition, but for our treatment of other sentient species.

|Gregory Berns: Decoding the Dog's Mind with Awake Neuroimaging

Gordon Burghardt: Probing the Umwelt of Reptiles

Jon Sakata: Audience Effects on Communication Signals

PANEL 1: Reptiles, Birds and Mammals

WORKSHOP 1: Kristin Andrews: The "Other" Problems: Mind,

Behavior, and Agency

Sarah Brosnan: How Do Primates Feel About Their Social

Partners?

Alexander Ophir: The Cognitive Ecology of Monogamy

Michael Hendricks: Integrating Action and Perception in a Small

Nervous System

PANEL 2: Primates, Voles and Worms

WORKSHOP 2: Jonathan Birch: Animal Sentience and the

Precautionary Principle

Malcolm Maclver: How Sentience Changed After Fish Invaded

Land 385 Million Years Ago

Sarah Woolley: Neural Mechanisms of Preference in Female

Songbird

Simon Reader: Animal Social Learning: Implications for

Understanding Others

PANEL 3: Sea to Land to Air

WORKSHOP 3: Steven M. Wise: Nonhuman Personhood

Tomoko Ohyama: Action Selection in a Small Brain (Drosophila

Maggot)

Mike Ryan: "Crazy Love": Nonlinearity and Irrationality in Mate

Choice

Louis Lefebvre: Animal Innovation: From Ecology to

Neurotransmitters

PANEL 4: Maggots, Frogs and Birds: Flexibility Evolving

SPECIAL EVENT: Mario Cyr: Polar Bears

Colin Chapman: Why Do We Want to Think People Are

Different?

Vladimir Pradosudov: Chickadee Spatial Cognition

Jonathan Balcombe: The Sentient World of Fishes

PANEL 5: Similarities and Differences

WORKSHOP 5 (part 1): Gary Comstock: A Cow's Concept of

Her Future

WORKSHOP 5 (part 2): Jean-Jacques Kona-Boun: Physical

and Mental Risks to Cattle and Horses in Rodeos
Joshua Plotnik: Thoughtful Trunks: Application of Elephant Cognition for Elephant Conservation

Lori Marino: Who Are Dolphins?

Larry Young: The Neurobiology of Social Bonding, Empathy and Social Loss in Monogamous Voles

Panel 6: Mammals All, Great and Small

WORKSHOP 6: Lori Marino: The Inconvenient Truth About

Thinking Chickens

Andrew Adamatzky: Slime Mould: Cognition Through

Computation

Frantisek Baluska \& Stefano Mancuso: What a Plant Knows and Perceives

Arthur Reber: A Novel Theory of the Origin of Mind:

Conversations With a Caterpillar and a Bacterium

PANEL 7: Microbes, Molds and Plants

WORKSHOP 7: Suzanne Held \& Michael Mendl: Pig Cognition and Why It Matters

James Simmons: What Is It Like To Be A Bat?

Debbie Kelly: Spatial Cognition in Food-Storing

Steve Phelps: Social Cognition Across Species

PANEL 8: Social Space

WORKSHOP 8: To be announced

Lars Chittka: The Mind of the Bee

Reuven Dukas: Insect Emotions: Mechanisms and Evolutionary Biology

Adam Shriver: Do Human Lesion Studies Tell Us the Cortex is

Required for Pain Experiences?

PANEL 9: The Invertebrate Mind

WORKSHOP 9: Delcianna Winders: Nonhuman Animals in

Sport and Entertainment

Carel ten Cate: Avian Capacity for Categorization and

Abstraction

Jennifer Mather: Do Squid Have a Sense of Self?

Steve Chang: Neurobiology of Monkeys Thinking About Other Monkeys

PANEL 10: Others in Mind

WORKSHOP 10: The Legal Status of Sentient Nonhuman

Species 